\title{
The Pandemic COVID-19 and the Auspicious Role of Frontier Pharmacists against This Global Threat
}

\author{
Md Jahidul Hasan ${ }^{*}{ }^{\mathbb{D}}$, Jaime Nead ${ }^{2}$ \\ ${ }^{1}$ Clinical Pharmacy Services, Department of Pharmacy, Square Hospitals Ltd., Dhaka, Bangladesh \\ ${ }^{2}$ Department of Pharmacy, Children's Hospital of Eastern Ontario, Ottawa, Canada \\ Email: `jahidul@squarehospital.com, jnead@cheo.on.ca
}

How to cite this paper: Hasan, M.J. and Nead, J. (2020) The Pandemic COVID-19 and the Auspicious Role of Frontier Pharmacists against This Global Threat. Pharmacology \& Pharmacy, 11, 209-225. https://doi.org/10.4236/pp.2020.119019

Received: July 24, 2020

Accepted: September 12, 2020

Published: September 15, 2020

Copyright $\odot 2020$ by author(s) and Scientific Research Publishing Inc. This work is licensed under the Creative Commons Attribution International License (CC BY 4.0).

http://creativecommons.org/licenses/by/4.0/ (c) (i) Open Access

\section{Abstract}

The frontline pharmacists during this pandemic COVID-19 (coronavirus disease 2019) situation are potentially contributing to saving human lives worldwide. The objective of this study was to demonstrate the current contributions of pharmacists among the frontline healthcare professionals in the management of the COVID-19 crisis across the world. MEDLINE, EMBASE, Cochrane Database of Systematic Reviews, Web of Science, and Scopus databases were searched for this study from March 20, 2020 to May 20, 2020. The basic keyword "pharmacist and COVID-19" was used to select studies. Relevant English-language studies, guidelines, articles, relevant published reports in different online news portals and official web pages of different organizations were searched. Pharmacists in the United States and United Kingdom are testing patients for COVID-19 and providing medical advice to patients. Community pharmacists in European countries are focused on the smooth supply of essential medicines, and working to build awareness regarding the community transmission of COVID-19. Hospital and clinical pharmacists are working to facilitate the effective medication therapy management for improving the clinical outcomes of COVID-19 patients. Pharmacists in low-and middle-income countries around the world have focused their efforts mainly on awareness-building activities regarding the community transmission of COVID-19, and the mass production of alcohol-based hand-sanitizer. Several resources are globally available for pharmacists to improve their competency and self-protection from COVID-19. Frontline pharmacists are enthusiastically contributing in the prevention and treatment of COVID-19 from a community-to-clinical level worldwide. Their active participation as a member of the frontline healthcare team is crucial in order to address and overcome the challenges that this pandemic has created, and to tackle this global 
healthcare crisis efficiently.

\section{Keywords}

Pharmacist, Frontline, Pandemic COVID-19, Healthcare Professionals

\section{Introduction}

The first case of the coronavirus disease 2019 (COVID-19) outbreak caused by the severe acute respiratory syndrome coronavirus 2 (SARS-CoV-2), a highly transmittable novel beta coronavirus, was detected in Wuhan, China in December 2019, and spread shortly to many countries around the world [1] [2]. The World Health Organization (WHO) recognized the severity of COVID-19 worldwide, first declaring this threat as a "public health emergency of international concern" in January 2020, and then as a "pandemic" threat to global human health on 11 March 2020 [3]. As of 30 June 2020, more than 101.85374 confirmed COVID-19 cases have been reported in more than 200 countries with 5.03862 deaths [4].

In countries experiencing COVID-19 outbreaks, local governments have issued "lockdown" areas considering the risk of corona virus spreading which in turn restricts the movements of people, schooling activities, local trades, and all kinds of social gathering, with the exception of health-related emergencies [5]. At this moment when human lives are under serious threat due to this global crisis, healthcare professionals, including all subspecialties of pharmacists are active in the pandemic COVID-19 battlefield worldwide [6] [7]. Primary healthcare providers (PHPs), including doctors and nurses have taken on the significant medical challenges that this pandemic has created, risking their own health in order to treat patients with COVID-19 in healthcare settings that are essential to save mankind from this serious COVID-19 threat on the earth [8]. Along with the contributions of PHPs, to ensure the required medications are available, proper dispensing of medications and effective medication therapy management of COVID-19 patients is important to tackle this crisis effectively. This responsibility is solely that of pharmacy professionals (pharmacist) that are the drug experts [9]. To amplify the quality of COVID-19 patient care, to support the mass population in the communities, and to reduce the COVID-19-associated mortality, the roles of pharmacists are of great importance and these realities have been evident worldwide [6] [8] [9]. The aim of this study is to focus on the potential contributions of pharmacists as frontline healthcare professionals involved in direct patient care in order to tackle this global COVID-19 pandemic effectively.

\section{Methods}

The following electronic databases: MEDLINE, EMBASE, Cochrane Database of Systematic Reviews, Web of Science, and Scopus databases were searched by selecting the references of relevant reviews to select articles published in Eng- 
lish up to 25 April 2020 in order to prepare this review article. The following keywords were used with each database: "pharmacist AND COVID-19" with or without the terms- "healthcare professionals", "roles", "contributions", "low-and-middle income countries", "guidelines", "death", and "protection". In addition, recent online reports/articles published in English from January 1, 2020 to June 30, 2020 related to the roles of pharmacists in pandemic COVID-19 in different online news portals and official web pages of different organizations throughout the world were also considered as the common source of references for this review article. Figure 1 illustrates the process of the relevant reference selection in this study.

\section{Learning from Previous Pandemic Attacks}

Over the last 100 years, the world has experienced multiple pandemic viral attacks against the human population. In 1918, around 50 million people (one-third of the total world population at that time) were affected by the "Spanish flu" (H1N1 influenza virus). As a frontline healthcare provider, pharmacists willingly accept the challenges to tackle this pandemic crisis present in Europe, the United

\section{(1) Electronic databases}

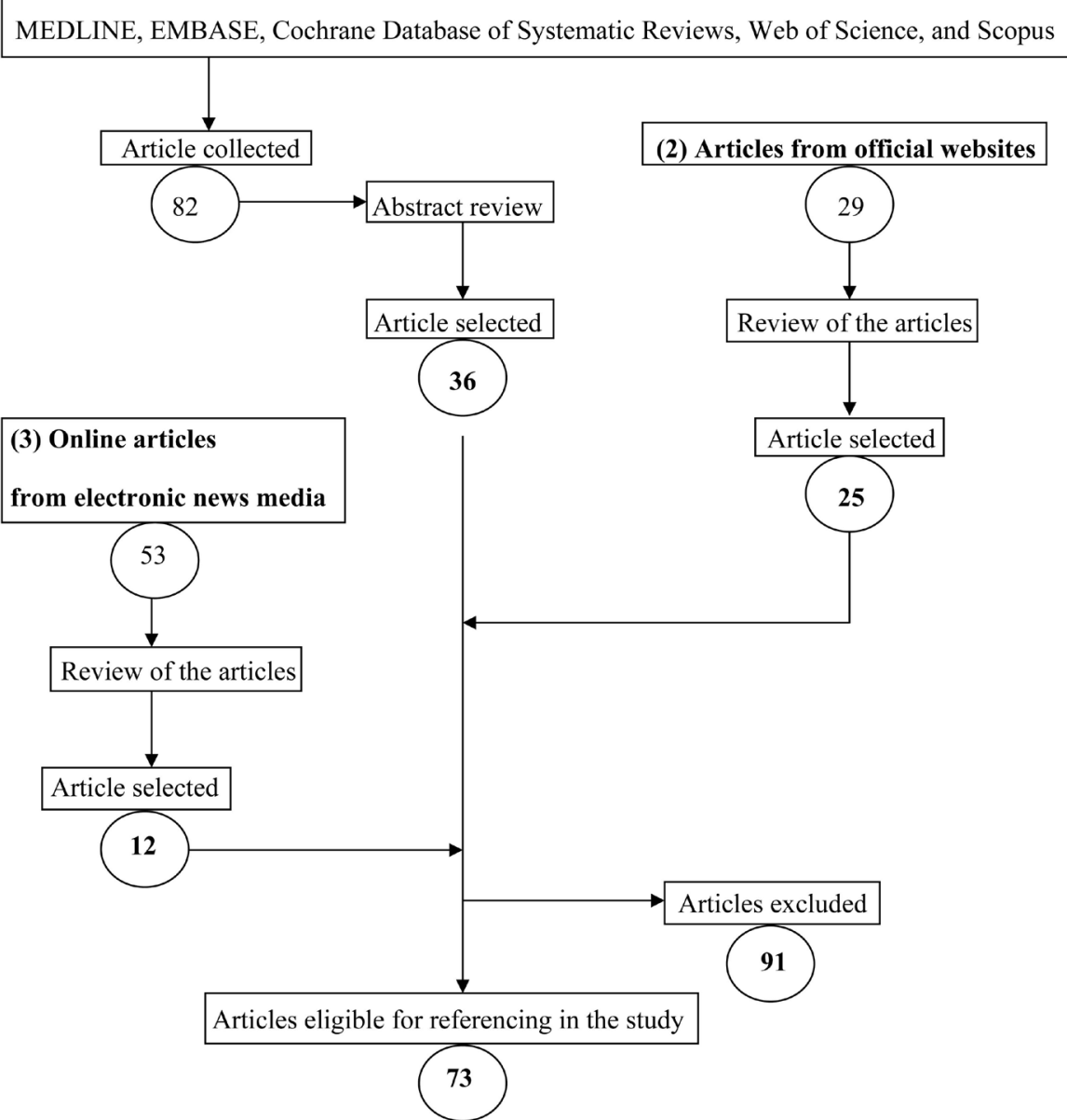

Figure 1. Study design and the process of relevant reference selection for the study. 
States of America (USA) and some parts of Asia. An estimated 20 to 50 million people lost their lives as a result of this pandemic. In 1957, the "Asian flu", also called H2N2 influenza virus, caused death in 1 to 1.5 million people worldwide [10]. Just 10 years later, the world faced another pandemic, the "Hong Kong flu", also known as $\mathrm{H} 3 \mathrm{~N} 2$ influenza virus, which resulted in nearly one million lost lives. In the early part of the twenty-first century, the first pandemic threat of coronavirus by its strain "severe acute respiratory syndrome coronavirus (SARS-CoV)" was seen in 2003 with a case-fatality rate of $11 \%$ [10] [11]. "Swine flu", also known as H1N1 influenza virus, was discovered in Mexico and the U.S. in 2009, and spread to many parts of the world within a short time resulting in the deaths of 0.15 to 0.57 million people worldwide [11]. The second threat from another strain of coronavirus came in 2012 in the name of Middle East respiratory syndrome coronavirus (MERS-CoV), when 2494 people in 27 different countries were affected with a case-fatality rate of $34.4 \%$ [1] [12]. The third coronavirus attack within 20 years commenced at the end of 2019. Considered the most virulent strain, the "severe acute respiratory syndrome coronavirus 2 (SARS-CoV-2)" has resulted in a global human health crisis within a very short period of time, and is still moving at an unprecedented speed [2] [12].

Healthcare professionals, including pharmacists of all specialties, have played an important role on the frontlines against these pandemic attacks, and have provided treatments and other healthcare supports to people in communities around the world in order to overcome these pandemic crises [11] [12] [13]. Australian community pharmacists have provided vast amounts of people in their communities with essential health services, and pharmacists of different specialties greatly contributed in the national pandemic planning and in direct patient care during the pandemic Swine flu attack in 2009 [13]. Pharmacy students in U.S. played a frontline role by providing necessary pandemic Swine flu information and education to patients, and their direct participation in H1N1 vaccination was highly appreciated by the patients [14]. In Canada, during the SARS pandemic in 2013, the newly recruited hospital and community pharmacists joined the frontline healthcare team in fighting against the viral threat, by ensuring proper medication dispensing and other necessary pharmaceutical care directly to the patients that potentially contributed to patient care [15]. These pharmacists also gathered significant amounts of knowledge and experience on the management of serious pandemic threats, including acutely developed critical patient management and treatment policies [15], which improved their level of skills and expertise, leading to become a potential frontline-fighter for upcoming threats management, such as COVID-19. A study in Saudi Arabia showed that pharmacists working with PHPs in the treatment of critically ill patients with MERS played a potential role in the clinical decision-making and effective medication therapy management system with good knowledge on disease (88.9\%; just below the physicians (95.7\%)), and positive attitude (94.4\%) towards the crisis situation, which was second highest after physicians' level [16]. Thus, being a drug and clinical decision making expert, pharmacists in hospital envi- 
ronments participated in the frontline patient care team in all pandemic situations to minimize the severity of the threats. By providing drug information and pharmacy supports to people in the community, community pharmacists around the world contributed significantly in resisting the progression of the disease among communities, and to save human lives from the pandemic attacks. In addition, from all the previous pandemic experience, pharmacists gathered huge knowledge, experience and skills which they are utilizing in the management of the current COVID-19 pandemic worldwide [9] [17].

\section{Pharmacists as Frontline-Healthcare Professionals}

Behind the pandemic feature of COVID-19, which was first identified simply as "pneumonia with unknown etiology" in China, the SARS-CoV-2 (the mutant version of SARS-CoV) is able to spread at a fast rate between humans via droplet transmission and direct contact, has high capacity of genetic diversification and frequent genomic recombination, and has tremendous potential to act in human-animal interface [18] [19] [20]. The accelerated transmission rate and pathogenicity of COVID-19 throughout the world population has allowed this disease pandemic to have an increased mortality rate [21].

In response, pharmacists in most of the affected countries have come in the COVID-19 battlefield with their own expertise and interest among the communities, as well as in healthcare setups as a core team member with the PHPs. Their contributions for the effective manage of this global crisis are not only limited to their daily work responsibilities in their own institutions, but also have been extended to a more life-saving approach [6] [8]. Pharmacists having adequate knowledge on COVID-19 epidemiology, its transmission factors, its susceptibility to available drugs, possible community transition points, and its preventive measures, and are therefore considered as one of the best fighters against COVID-19. As a member in the primary healthcare workforce, pharmacists' roles in community healthcare systems, public awareness programs, and in direct patient care management have been distinguished worldwide, and by this time, pharmacists have been recognized as a potential healthcare professional among the frontline individuals during this global pandemic crisis [6] [7] [22] [23]. The contributions of different specialized pharmacy groups from community-to-clinical in the COVID-19 prevention and treatment are discussed below.

\section{Community Pharmacists}

The conceptual definition of community pharmacist mostly used in the modern countries is the specialized pharmacist who plays roles either retail pharmacies in the communities or outpatient pharmacies in primary healthcare environments. A community pharmacist most often deals with dispensing prescription medications, patient counseling, providing drug information to its users, and other pharmacy supports to the community for the goal of improvement of the community healthcare system [23]. In community healthcare systems around 
the world, pharmacists are the most accessible healthcare provider widely distributed among the vast communities, and their active participation in the current pandemic has supported mass community people greatly [23] [24]. The SARS-CoV-2 has an incubation period of 2 - 14 days, with early mild to moderate symptoms that include fever, dry cough, myalgia, fatigue and shortness of breath, and in severe cases, acute respiratory distress syndrome, pneumonia, septic shock, acute kidney injury and secondary infections have been reported [1] [2] [3].

In the community healthcare system in most of the developed and developing countries, people preferentially seek the aid of pharmacists in community as a first line for pharmaceutical support, and there, they share their discomforts of suspected diseases, including COVID-19, which may be the first disclosure of the symptoms of COVID-19. In such cases, community pharmacists are the first point of contact, thereby providing necessary suggestions and direction to those suspected COVID-19 patients for an emergency response, and this pivotal role of community pharmacists has a magnificent impact in saving human lives from this pandemic [23] [24] [25] [26].

In the USA, in the midst of COVID-19 crisis, frontline community pharmacists are playing a pivotal role in nation-wide pandemic management by ensuring ongoing pharmacy services, testing for COVID-19, and treating people with chronic diseases as an efficient healthcare professional in primary point-of-care (Table 1), which is essential to tackle the crisis situation competently [27] [28] [29]. A very similar picture of frontline community pharmacists' contributions has been illustrated in the United Kingdom (U.K.) (Table 1), which helped the U.K. to develop a strong defense against the COVID-19 pandemic [30] [31] [32]. The roles of community pharmacists in many countries currently struggling with the COVID-19 pandemic, including Spain, New Zealand, Italy, France, China, Canada and Australia (Table 1) are to provide support in order to reduce the community transmission of COVID-19 efficiently and to enhance the strength of primary care teams for the management of unprecedented COVID-19 cases [27]-[41]. As a result of these efforts, their contributions have come under the spotlight because of their strong frontline-position to assuage this global pandemic crisis.

\section{Role of Hospital and Clinical Pharmacists}

According to China's recent COVID-19 outbreak management experience, hospitalization of the confirmed COVID-19 patients in designated hospitals having standard triage system, expert primary and allied healthcare professionals, adequate healthcare facilities, and standardized inpatient treatment guidelines are highly recommended [42]. A comprehensive treatment protocol and a standardized management system for COVID-19 patients have yet to be established elsewhere, but are very important to attenuate the current virulence of COVID-19. Therefore, a competent multidisciplinary team-based management system is 
Table 1. Contributions of community pharmacists during the pandemic COVID-19 [4] [17] [27]-[41].

\begin{tabular}{|c|c|c|}
\hline Country & $\begin{array}{l}\text { COVID-19 insights } \\
\text { (up to June } 30,2020 \text { ) }\end{array}$ & Highlighted contributions \\
\hline United States of America & $\begin{array}{l}\text { Total confirmed cases: } 2,537,636 \\
\text { Total deaths: } 126,203 \\
\text { TC: Community transmission }\end{array}$ & $\begin{array}{l}\text { - Providing basic hygiene, health and pharmaceutical needs from pharmacy (last } \\
\text { community-resort), and effectively tackling the life-saving drug-shortage events } \\
\text { - Testing COVID-19 in community pharmacies } \\
\text { - Giving point-of-care testing services and treatments for common cold, flu and } \\
\text { allergy-related symptoms } \\
\text { - In many States, they are suggesting tests for diseases and giving treatments to } \\
\text { patients with chronic diseases }\end{array}$ \\
\hline United Kingdom & $\begin{array}{l}\text { Total confirmed cases: } 311,969 \\
\text { Total deaths: } 43,575 \\
\text { TC: Community transmission }\end{array}$ & $\begin{array}{l}\text { - Providing basic pharmacy and health supports to community peoples, and } \\
\text { ensuring a smooth essential drug-supply during this period of unprecedented } \\
\text { medicinal demand } \\
\text { - Giving rapid COVID-19 testing service from community pharmacies } \\
\text { - Supporting the community health by giving medical advices to patients and by } \\
\text { effective patient counseling }\end{array}$ \\
\hline Spain & $\begin{array}{l}\text { Total confirmed cases: } 248,970 \\
\text { Total deaths: } 28,346 \\
\text { TC: Pending }\end{array}$ & $\begin{array}{l}\text { - Providing all-sort of pharmaceutical care to community people under the } \\
\text { shortage of personal protective equipment (PPE) }\end{array}$ \\
\hline New Zealand & $\begin{array}{l}\text { Total confirmed cases: } 1178 \\
\text { Total deaths: } 22 \\
\text { TC: Clusters of cases }\end{array}$ & $\begin{array}{l}\text { - Providing one-stop pharmacy service including home delivery service from the } \\
\text { community pharmacies to avoid public gathering } \\
\text { - Disseminating information to community people regarding hand-hygiene, } \\
\text { personal protection and community transmission of COVID-19 }\end{array}$ \\
\hline Italy & $\begin{array}{l}\text { Total confirmed cases: } 240,436 \\
\text { Total deaths: } 34,744 \\
\text { TC: Community transmission }\end{array}$ & $\begin{array}{l}\text { - Serving community people without hampering the smooth supply of essential } \\
\text { medicines } \\
\text { - Ensuring pharmaceutical care at every door by developing "home delivery } \\
\text { service" which is resisting people to come out under lockdown }\end{array}$ \\
\hline France & $\begin{array}{l}\text { Total confirmed cases: } 156,930 \\
\text { Total deaths: } 29,730 \\
\text { TC: Community transmission }\end{array}$ & $\begin{array}{l}\text { - Beside ensuring the smooth supply of essential medicines, they are increasing } \\
\text { awareness among the people regarding social distance } \\
\text { - Effectively tackling the crisis moment of basic hygiene, pharmaceuticals and } \\
\text { protective equipments }\end{array}$ \\
\hline China & $\begin{array}{l}\text { Total confirmed cases: } 85,227 \\
\text { Total deaths: } 4,648 \\
\text { TC: Clusters of cases }\end{array}$ & $\begin{array}{l}\text { - Being a pharmaceutical care provider, they have established the community } \\
\text { pharmacies as a point-of-all medicinal resources, and ensuring patients' } \\
\text { medication safety } \\
\text { - Ensuring adequate national stock of essential medicines } \\
\text { - Organizing remote pharmacy services to prevent community transmission of } \\
\text { COVID-19 }\end{array}$ \\
\hline Canada & $\begin{array}{l}\text { Total confirmed cases: } 103,250 \\
\text { Total deaths: } 8,522 \\
\text { TC: Community transmission }\end{array}$ & $\begin{array}{l}\text { - Ensuring a smooth supply of essential medicine throughout the country } \\
\text { - Testing COVID-19 on priority basis } \\
\text { - Working as a frontline care provider and increasing awareness on COVID-19 } \\
\text { among the community people } \\
\text { - In Quebec State, they are extending prescriptions and prescribing certain } \\
\text { medications along with doctors for limiting public movements at this pandemic } \\
\text { situation }\end{array}$ \\
\hline Australia & $\begin{array}{l}\text { Total confirmed cases: } 7,767 \\
\text { Total deaths: } 104 \\
\text { TC: Clusters of cases }\end{array}$ & $\begin{array}{l}\text { - Playing a pivotal role in the awareness building programs on COVID-19 among } \\
\text { the community people } \\
\text { - Preparing and dispensing large-volume alcohol-based hand sanitizer } \\
\text { - Providing all kind of COVID-19 related information from the community } \\
\text { pharmacies as an "central information center" }\end{array}$ \\
\hline
\end{tabular}

TC: transmission classification.

crucial for hospitals in countries with COVID-19 outbreaks in order to handle the COVID-19 patients, effectively [43] [44]. 
Hospital pharmacists are one of the key frontline players in the COVID-19 challenge being faced worldwide, and their potential role in pharmaceutical care services under a collaborative medical team for the treatment of COVID-19 patients in hospitals is essential [26]. According to the Centers for Disease Control and Prevention (CDC) in the United States, after confirmation of COVID-19 in a patient, they will be immediately admitted to a pre-designated hospital through a proper TRIAGE system for centralized and appropriate treatment. Currently, there is no recommendation from the WHO regarding any medication with proven efficacy for the treatment of COVID-19. Different drugs of different therapeutic classes (commercially available or those being used in clinical trials) are being used in the treatment of COVID-19 sporadically worldwide with a lot of controversy regarding efficacy and safety, as well as the associated drug-shortages that are a result of their use. During this climacteric time, hospital pharmacists, who are responsible for dispensing appropriate prescription medicines, maintaining an uninterrupted supply of essential medicines, providing drug information, and ensuring medication safety, are working under enormous mental and physical challenges due to frequent drug-shortages, lack of information about the use of medications in off-label indication in COVID-19 treatment and prevention, and for occupational COVID-19 infection [45] [46]. However, having all these crucial challenges during this pandemic situation, hospital pharmacists around the world position themselves in the frontline care-giving team, fearlessly tackling this crisis head-on [23] [46].

According to the strategic guideline "CORONAVIRUS SARS-CoV-2 INFECTION: Expert Consensus on Guidance and Prevention Strategies for Hospital Pharmacists and the Pharmacy Workforce (2nd Edition)" developed by the Chinese Pharmaceutical Association for environment control strategies and staff protection [47], Chinese hospital pharmacists have taken several sensible initiatives in hospital pharmacy areas, including: cleaning the pharmacy environment properly with selective disinfectants; the use of PPEs for self-protection; development of new workflows for proper handling of the COVID-19 pandemic; effective planning for managing drug-shortage events; and development of emergency protocols for dispensing inpatient prescriptions smoothly [22]. According to the American Society of Health-System Pharmacists (ASHP), hospital pharmacists in United States during the COVID19 pandemic, are developing and disseminating up-to-dated clinical guidelines, COVID-19 treatment-associated drug information and sharing real-time case-by-case experience to frontline healthcare professionals, including pharmacists in order to combat this pandemic crisis efficiently. Moreover, the newly developed "COVID-19 Resource Center" is extensively supporting all the frontline caregivers by providing direction on clinical management of COVID-19, health tips, and all types of drug information [48]. Through a remarkable collaborative relationship, pharmacists in the U.K. and Pakistan have jointly developed a 10-step protection guideline in both English and Urdu language, made especially for the frontline pharmacists in Pakistan with the goal of reducing the community transmission of COVID-19 
and to ensure personal-protection at working stations in response to the COVID-19 pandemic in Pakistan [38].

The use of new investigational drugs in the treatment of COVID-19 is troublesome and needs approval from different sides. In contrary, conventional drugs having antiviral properties are relatively easy to apply for COVID-19 treatment, but their efficacy against COVID-19 is still unclear. On 1 May 2020, the Food and Drug Administration (FDA) in the United States was the first to temporarily legalize the use of the investigational antiviral drug remdesivir for the treatment of severe COVID-19 in adults and children under an emergency use authorization. Remdesivir's safety and efficacy data are very limited [51]. Other drug therapies for treatment of COVID-19 including, favipiravir, hydroxychloroquine, chloroquine phosphate, interferon $\alpha$ (IFN- $\alpha$ ), lopinavir/ritonavir, tocilizumab, ribavirin, and arbidol have come under consideration in the development of many clinical COVID-19 treatment guidelines around the world, but none of these drugs have yet been approved for the treatment of COVID-19 [49] [50]. The application of these drugs in COVID-19 patients within clinical trials is a very challenging issue for clinical pharmacists, who are responsible for patients' medication therapy management system [49].

Clinical pharmacists are considered an essential clinical investigation-team member for the successful accomplishment of a clinical trial. During this global pandemic situation, to identify an effective drug in the treatment and/or prevention of COVID-19 on urgent-basis, the promising roles of frontline clinical pharmacists around the world have come in the global concern. During the clinical trial of remdesivir in the US, clinical pharmacists were primarily involved in the clinical assessment process of the patients for study, taking patients' previous drug/disease history, communication with different stakeholders for study approval, expert-opinion in the clinical decision-making, and obtaining patient consent [49]. The National Health Service (NHS) of the U.K. has developed an experienced pharmacist-based clinical assessment service (CAS) as of 16 April 2020 where redeployed pharmacists from distinct locations of NHS, and pharmacists who have voluntarily returned to work in CAS (Clinical Assessment Service) are responsible for delivering urgent primary care services, responding to NHS's queries, answering to queries from suspected COVID-19 patients, and urgently responding to queries from the general people [50].

In global perspective, clinical pharmacists are playing a significant role in the care of patients with COVID-19 by participating in the developmental process of national/hospital-based clinical COVID-19 treatment guidelines, giving drug information to PHPs, monitoring drug administration, suggesting alternative drug therapies, giving supports to other healthcare professionals, and drug safety monitoring to enhance the quality of patient care [49] [51] [52] [53]. Moreover, in response to this global pandemic crisis, clinical pharmacists on the frontlines around the world are putting their full concentration in the effective treatment of COVID-19 patients, and henceforth, their potential contributions to attenuate this COVID-19 pandemic have been appreciated worldwide [49] [50] [52]. 


\section{Role of Pharmacists in Low-and-Middle Income Countries}

Healthcare systems in low-and middle-income countries (LMICs) have struggled with numerous difficulties, including limited access to universal health coverage, substandard quality of patient care, shortage of medicines, inadequate healthcare professionals, limited financial supports, and insufficient budgets for healthcare system development. The current COVID-19 pandemic has worsened these crises in LMICs greatly resulting in increased challenges especially for the people living near the poverty level [54] [55] [56] [57] [58]. The roles of pharmacists in LMICs are mostly limited to drug dispensing, patient counseling, disseminating drug information, and drug-drug interaction monitoring [56] [57] [58] [59]. In response to the COVID-19 crisis in LMICs, community, hospital and clinical pharmacists of these countries have come to the frontline as an efficient healthcare provider to effectively tackle the increasing crises associated with this pandemic [60].

Pharmacists in India are advancing to incorporate COVID-19 testing service for its people in the communities [61]. In Pakistan, pharmacists are giving free-of-cost health advice and services to the general population from the community pharmacies. In addition, pharmacists are active on telehealth and telemedicine services along with doctors, allowing people to easily access necessary information from their healthcare provider without being physically present [38].

In order to tackle the current local shortage of alcohol-based hand rubs/sanitizers, pharmacists are preparing low-cost large volume alcohol-based hand sanitizers in different hospital and community pharmacies [62], and pharmacy students of different public and private universities are also preparing alcohol-based hand rubs/sanitizers for local people and healthcare professionals as free-of-cost to assist in the fight against COVID-19 [63] [64]. Pharmacists of International Rescue Committee (IRC) are providing medicines for reproductive health, supplements, and healthcare supports to women within the Azraq refugee camp in Jordan during the country-wide lockdown due to COVID-19 [65]. Recent experiences from the epidemic Ebola virus management in many Africa countries have helped to prepare African pharmacists to face the challenges of the COVID-19 pandemic, and to handle this global crisis within their communities [66]. Thus, the fundamental roles of the frontline pharmacists in LMICs are essential for countries to develop a competent multidisciplinary healthcare professional team to efficiently combat the challenges of the COVID-19 pandemic, including its fast transmission between communities, associated health complications, socioeconomical dilapidation, and mortality [67]-[73].

\section{Current Resources for Pharmacists}

The deaths of frontline pharmacists from COVID-19 infections contaminated during their close contact with COVID-19 positive patients in their workplace, is very grievous news. Pharmacists working on the frontline naturally come in 
Table 2. Resources for pharmacists to combat pandemic COVID-19 crisis [67]-[73].

\begin{tabular}{|c|c|c|}
\hline Resource & Organization & Link \\
\hline COVID-19 resource center & $\begin{array}{l}\text { American Society of Health-System } \\
\text { Pharmacists (ASHP), United States }\end{array}$ & https://www.ashp.org/COVID-19 \\
\hline Pharmacists' Guide to Coronavirus & $\begin{array}{l}\text { American Pharmacists Association } \\
(\mathrm{APhA}), \text { United States }\end{array}$ & $\underline{\text { https://www.pharmacist.com/coronavirus }}$ \\
\hline EAHP COVID-19 Resource Centre & $\begin{array}{l}\text { European association of hospital } \\
\text { pharmacists (EAHP) }\end{array}$ & $\begin{array}{l}\text { https://www.eahp.eu/hp-practice/hospital-pharmacy/eahp- } \\
\underline{\text { covid-19-resource-centre }}\end{array}$ \\
\hline $\begin{array}{l}\text { Guidelines for pharmacists and the pharmacy } \\
\text { workforce }\end{array}$ & $\begin{array}{l}\text { International Pharmaceutical } \\
\text { Federation (FIP) }\end{array}$ & $\begin{array}{l}\text { https://www.fip.org/files/content/priority-areas/coronaviru } \\
\text { s/COVID-19-Guidelines-for-pharmacists-and-the-pharma } \\
\text { cy-workforce.pdf }\end{array}$ \\
\hline $\begin{array}{l}\text { Considerations for pharmacies during the } \\
\text { COVID-19 pandemic }\end{array}$ & $\begin{array}{l}\text { Centers for Disease Control and } \\
\text { Prevention (CDC), United States }\end{array}$ & $\begin{array}{l}\text { https://www.cdc.gov/coronavirus/2019-ncov/healthcare-res } \\
\text { ources/pharmacies.html }\end{array}$ \\
\hline $\begin{array}{l}\text { Rational use of personal protective equipment } \\
\text { (PPE) for coronavirus disease (COVID-19) }\end{array}$ & World Health Organization (WHO) & $\begin{array}{l}\text { https://apps.who.int/iris/bitstream/handle/10665/331498/ } \\
\underline{\text { WHO-2019-nCoV-IPCPPE_use-2020.2-eng.pdf }}\end{array}$ \\
\hline $\begin{array}{l}\text { Risk assessment and management of exposure } \\
\text { of health care workers in the context of } \\
\text { COVID-19 }\end{array}$ & World Health Organization (WHO) & $\begin{array}{l}\text { https://apps.who.int/iris/bitstream/handle/10665/331496/ } \\
\underline{\text { WHO-2019-nCov-HCW_risk_assessment-2020.2-eng.pdf }}\end{array}$ \\
\hline
\end{tabular}

close contact of positive COVID-19 patients, and at that time, they, like other frontline healthcare professionals, are mostly vulnerable to be infected by the coronavirus if they do not have access to the proper PPEs [17] [38]. Italy lost eight brave community pharmacists working on frontline for the same reason [33]. To avoid the risk of coronavirus contamination from positive patients, frontline pharmacists should have to follow the self-protection guidelines strictly, work-stations should be designed and cleaned properly, and their working protocols should be up-to-date concerning the current characteristics of COVID-19 [17].

As for global resources for pharmacists, there are guidelines available (Table 2) that can be considered essential to follow for the protection of frontline pharmacists who have the potential to frequently come into the contact with positive COVID-19 patients [2] [17] [22]. To date, all the potential roles of pharmacists from different corners of the world have already established this sense that to efficiently mitigate this pandemic crisis worldwide, pharmacists' active participation is highly necessary in the frontline healthcare team.

\section{Conclusion}

Pharmacists play an important role as frontline healthcare professionals in helping to reduce the global spread of COVID-19. Being a drug-expert, pharmacists' involvement in the frontline healthcare team enhances the overall capacity of the team to fight against this serious threat to global human health. In addition, the contributions of these frontline-fighter pharmacists in the treatment and prevention of the COVID-19 pandemic have lessened the stresses and work-burden of primary healthcare providers worldwide significantly. 


\section{Acknowledgements}

The authors of this study are grateful to the authority and pharmacists of Square hospital ltd., Dhaka, Bangladesh for providing all kind of technical supports for data collection of this study.

\section{Author's Contributions}

Md Jahidul Hasan: study design, data collection, data analyses, manuscript drafting and editing, manuscript finalization.

Jaime Nead: Manuscript editing, Revised the manuscript critically for important intellectual contents.

\section{Conflicts of Interest}

The authors declare that they have no competing interests.

\section{References}

[1] Verity, R., Okell, L.C., Dorigatti, I, Winskill, P., Whittaker, C. and Imai, N. (2020) Estimates of the Severity of Coronavirus Disease 2019: A Model-Based Analysis. The Lancet Infectious Diseases, 20, 669-677. https://doi.org/10.1016/S1473-3099(20)30243-7

[2] The Lancet Infectious Diseases (2020) COVID-19, A Pandemic or Not? The Lancet Infectious Diseases, 20, 383. https://doi.org/10.1016/S1473-3099(20)30180-8

[3] Shereen, M.A., Khan, S., Kazmi, A., Bashir, N. and Siddique, R. (2020) COVID-19 Infection: Origin, Transmission, and Characteristics of Human Coronaviruses. Journal of Advanced Research, 24, 91-98. https://doi.org/10.1016/j.jare.2020.03.005

[4] World Health Organization (2020) Coronavirus Disease 2019 (COVID-19) Situation Report-162.

https://www.who.int/docs/default-source/coronaviruse/20200630-covid-19-sitrep-1 62.pdf?sfvrsn=e00a5466 2

[5] Colbourn, T. (2020) COVID-19: Extending or Relaxing Distancing Control Measures. The Lancet Public Health, 5, E236-E237. https://doi.org/10.1016/S2468-2667(20)30072-4

[6] Adams, J.G. and Walls, R.M. (2020) Supporting the Health Care Workforce during the COVID-19 Global Epidemic. JAMA, 323, 1439-1440.

https://doi.org/10.1001/jama.2020.3972

[7] The Lancet (2020) COVID-19: Protecting Health-Care Workers. The Lancet, 395, 922. https://doi.org/10.1016/S0140-6736(20)30644-9

[8] Ng, K., Poon, B.H., Puar, T.H.K., Quah, J.L.S., Loh, W.J., Wong, Y.J., Tan, T.Y. and Raghuram, J. (2020) COVID-19 and the Risk to Health Care Workers: A Case Report. Annals of Internal Medicine, 172, 766-767. https://doi.org/10.7326/L20-0175

[9] Kehrer, J.P., Eberhart, G., Wing, M. and Horon, K. (2013) Pharmacy's Role in A Modern Health Continuum. Canadian Pharmacists Journal, 146, 321-324. https://doi.org/10.1177/1715163513506370

[10] History.com Editors (2010) Spanish Flu. A and E Television Networks. https://www.history.com/topics/world-war-i/1918-flu-pandemic

[11] Al Hajjar, S. and McIntosh, K. (2010) The First Influenza Pandemic of the 21st 
Century. Annals of Saudi Medicine, 30, 1-10. https://doi.org/10.5144/0256-4947.59365

[12] Yang, Y., Peng, F., Wang, R., Yange, M., Guan, K., Jiang, T., Xu, G., Sun, J. and Chang, C. (2020) The Deadly Coronaviruses: The 2003 SARS Pandemic and the 2020 Novel Coronavirus Epidemic in China. Journal of Autoimmunity, 109, Article ID: 102434. https://doi.org/10.1016/j.jaut.2020.102434

[13] McCourt, E. (2020) Improving Pharmacist Involvement in Pandemic Influenza Planning and Response in Australia. Australian Healthcare and Hospitals Association. https://apo.org.au/sites/default/files/resource-files/2018-03/apo-nid136141.pdf

[14] Miller, S., Patel, N., Vadala, T., Abrons, J. and Cerulli, J. (2003) Defining the Pharmacist Role in the Pandemic Outbreak of Novel H1N1 Influenza. Journal of the American Pharmacists Association, 52, 763-767.

https://doi.org/10.1331/JAPhA.2012.11003

[15] Austin, Z., Martin, J.C. and Gregory, P.A. (2007) Pharmacy Practice in Times of Civil Crisis: The Experience of SARS and the Blackout in Ontario, Canada. Research in Social and Administrative Pharmacy, 3, 320-335.

https://doi.org/10.1016/j.sapharm.2006.09.001

[16] Albarrak, A.I., Mohammed, R., Al Elayan, A., Al Fawaz, F., Al Masry, M., Al Shammari, M. and Miaygil, S.B. (2019) Middle East Respiratory Syndrome (MERS): Comparing the Knowledge, Attitude and Practices of Different Health Care Workers. Journal of Infection and Public Health, in press. https://doi.org/10.1016/j.jiph.2019.06.029

[17] Liu, S., Luo, P., Tang, M., Hu, Q., Polidoro, J.P., Sun, S. and Gong, Z. (2020) Providing Pharmacy Services during the Coronavirus Pandemic. International Journal of Clinical Pharmacy, 42, 299-304. https://doi.org/10.1007/s11096-020-01017-0

[18] Cui, J., Li, F. and Shi, Z.L. (2019) Origin and Evolution of Pathogenic Coronaviruses. Nature Reviews Microbiology, 17, 181-192. https://doi.org/10.1038/s41579-018-0118-9

[19] Zhu, N., Zhang, D., Wang, W., Li, X., Yang, B., Song, J., Zhao, X., Huang, B., Shi, W., Lu, R., Niu, P., Zhan, F., Ma, X., Wang, D., Xu, W., Wu, G., Gao, G.F., Tan, W. and China Novel Coronavirus Investigating and Research Team (2020) A novel Coronavirus from Patients with Pneumonia in China, 2019. The New England Journal of Medicine, 382, 727-733. https://doi.org/10.1056/NEJMoa2001017

[20] Wu, D., Wu, T., Liu, Q. and Yang, Z. (2020) The SARS-CoV-2 Outbreak: What We Know. International Journal of Infectious Diseases, 94, 44-48. https://doi.org/10.1016/j.ijid.2020.03.004

[21] World Health Organization (2020) Rolling Updates on Coronavirus Disease (COVID-19). Events as They Happen.

https://www.who.int/emergencies/diseases/novel-coronavirus-2019/events-as-theyhappen

[22] Zheng, S.Q.,Yang, L., Zhou, P.X., Li, H.B., Liu, F. and Zhao, R.S. (2020) Recommendations and Guidance for Providing Pharmaceutical Care Services during COVID-19 Pandemic: A China Perspective. Research in Social and Administrative Pharmacy, in press. https://doi.org/10.1016/j.sapharm.2020.03.012

[23] Al-Quteimat, O.M. and Amer, A.M. (2020) SARS-CoV-2 Outbreak: How Can Pharmacists Help? Research in Social and Administrative Pharmacy, in press. https://doi.org/10.1016/j.sapharm.2020.03.018

[24] Ung, C.O.L. (2020) Community Pharmacist in Public Health Emergencies: Quick to Action against the Coronavirus 2019-nCoV Outbreak. Research in Social and Ad- 
ministrative Pharmacy, 16, 583-586. https://doi.org/10.1016/j.sapharm.2020.02.003

[25] Cadogan, C.A. and Hughes, C.M. (2020) On the Frontline against COVID-19: Community Pharmacists' Contribution during a Public Health Crisis. Research in Social and Administrative Pharmacy, in press.

https://doi.org/10.1016/j.sapharm.2020.03.015

[26] International Pharmaceutical Federation (2020) Coronavirus 2019-nCoV Outbreak. Information and Interim Guidelines for Pharmacists and the Pharmacy Workforce. https://www.fip.org/files/content/priority-areas/coronavirus/Coronavirus-guidance -update-ENGLISH.pdf

[27] Lentile, G. (2020) COVID-19: What Community Pharmacies Are Doing in the Hardest-Hit States.

https://www.drugtopics.com/coronavirus/covid-19-what-community-pharmacies-a re-doing-hardest-hit-states

[28] Department of Health and Human Services, United States. (2020) HHS Statements on Authorizing Licensed Pharmacists to Order and Administer COVID-19 tests. News.

https://www.hhs.gov/about/news/2020/04/08/hhs-statements-on-authorizing-licens ed-pharmacists-to-order-and-administer-covid-19-tests.html

[29] Murphy, E.M. (2020) Pharmacists Provide Care during COVID-19 Outbreak. News, the Ohio State University, College of Pharmacy.

https://pharmacy.osu.edu/news/pharmacists-provide-care-during-covid-19-outbrea $\underline{\mathrm{k}}$

[30] Pharmaceutical Services Negotiating Committee (2020) COVID-19 Testing for Pharmacy Staff (Updated).

https://psnc.org.uk/our-news/covid-19-update-testing-for-pharmacy-staff/

[31] Royal Pharmaceutical Society of Great Britain (2020) Coronavirus (COVID-19) Pharmacist Updates and Information. https://www.rpharms.com/coronavirus

[32] Department of Health and Social Care (2020) $£ 300$ Million Announced for Community Pharmacies to Support Them during Coronavirus Outbreak.

https://www.gov.uk/government/news/300-million-announced-for-community-pha rmacies-to-support-them-during-coronavirus-outbreak

[33] Shaw, I. (2020) COVID-19: Eight Community Pharmacy Staff in Spain Have Died. The Pharmacist.

https://www.thepharmacist.co.uk/covid-19/covid-19-eight-community-pharmacy-st aff-have-died-in-spain/

[34] Pharmaceutical Society of New Zealand (2020) COVID-19: Guidance Provided by the Society for Pharmacy.

https://www.psnz.org.nz/Story?Action=View\&Story id=111

[35] Pisano, G.P., Sadun, R. and Zanini, M. Lessons from Italy's Response to Coronavirus. Harvard Business Review.

https://hbr.org/2020/03/lessons-from-italys-response-to-coronavirus

[36] Pharmaceutical group of European Union (2020) COVID-19 Information Hub. https://www.pgeu.eu/covid-19-information-hub/

[37] Woods, M. (2020) Pharmacies on the Frontline as French Settle in for Covid-19 lockdown. FRI, France.

http://www.rfi.fr/en/france/20200318-pharmacies-on-frontline-as-french-settle-in-f or-covid-19-lockdown-coronavirus-panic-buying-masks-sanitiser-paracetamol

[38] Bukhari, N., Rasheed, H., Nayyer, B. and Babar, Z.U. (2020) Pharmacists at the Frontline Beating the COVID-19 Pandemic. Journal of Pharmaceutical Policy and 
Practice, 13, Article No. 8. https://doi.org/10.1186/s40545-020-00210-w

[39] College of Pharmacists of British Columbia (2020) Novel Coronavirus (COVID-19). https://www.bcpharmacists.org/covid19

[40] Staff, The Canadian Press (2020) COVID-19: Pharmacists Can Prescribe Some Medications. CTV News Montreal.

https://montreal.ctvnews.ca/covid-19-pharmacists-can-prescribe-some-medications $\underline{-1.4855578}$

[41] Cooper, R. What Pharmacists Need to Know about COVID-19. Australian Pharmacist.

https://www.australianpharmacist.com.au/what-pharmacists-need-to-know-about-c ovid-19/?doing wp cron=1587796567.3376290798187255859375

[42] National Health Commission of the People's Republic of China (2020) Working Plan on Prevention and Control of Novel Coronavirus Pneumonia. http://www.nhc.gov.cn/tigs/s7848/202001/808bbf75e5ce415aa19f74c78ddc653f.sht $\underline{\mathrm{ml}}$

[43] Zhou, F., Yu, T., Du, R., Fan, G., Liu, Y., Liu, Z., Xiang, J., Wang, Y., Song, B., Gu, X., Guan, L., Wei, Y., Li, H., Wu, X., Xu, J., Tu, S., Zhang, Y., Chen, H. and Cao, B. (2020) Clinical Course and Risk Factors for Mortality of Adult Inpatients with COVID-19 in Wuhan, China: A Retrospective Cohort Study. The Lancet, 395, 1054-1062. https://doi.org/10.1016/S0140-6736(20)30566-3

[44] Chen, T., Wu, D., Chen, H., Yan, W., Yang, D., Chen, G., Ma, K., Xu, D., Yu, H., Wang, H., Wang, T., Guo, W., Chen, J., Ding, C., Zhang, X., Huang, J., Han, M., Li, S., Luo, X., Zhao, J. and Ning, Q. (2020) Clinical Characteristics of 113 Deceased Patients with Coronavirus Disease 2019: Retrospective Study. The BMJ, 368, m1091. https://doi.org/10.1136/bmj.m1091

[45] Centers for Disease Control and Prevention, United States (2020) Interim Clinical Guidance for Management of Patients with Confirmed Coronavirus Disease (COVID-19).

https://www.cdc.gov/coronavirus/2019-ncov/hcp/clinical-guidance-management-pa tients.html

[46] Song, Z., Hu, Y., Zheng, S., Yang, L. and Zhao, R. (2020) Hospital Pharmacists' Pharmaceutical Care for Hospitalized Patients with COVID-19: Recommendations and Guidance from Clinical Experience. Research in Social and Administrative Pharmacy, in press. https://doi.org/10.1016/j.sapharm.2020.03.027

[47] Chinese Pharmaceutical Association (2020) Coronavirus SARS-CoV-2 Infection: Expert Consensus on Guidance and Prevention Strategies for Hospital Pharmacists and the Pharmacy Workforce. 2nd Edition. http://www.cpa.org.cn/cpadmn/attached/file/20200216/1581854567839722.pdf

[48] Abramowitz, P. (2020) New ASHP COVID-19 Updates. ASHP Connect, American Society of Health-System Pharmacists.

https://connect.ashp.org/blogs/paul-abramowitz/2020/04/24/new-ashp-covid-19-up dates

[49] Gross, A.E. and MacDougall, C. (2020) Roles of the Clinical Pharmacist during the COVID-19 Pandemic. Journal of the American College of Clinical Pharmacy, 3, 564-566. https://doi.org/10.1002/jac5.1231

[50] The Pharmaceutical Journal (2020) COVID-19 LATEST: Pharmacy Bid for Extra COVID-19 Funding Submitted to Government.

https://www.pharmaceutical-journal.com/news-and-analysis/news-blog/covid-19-la test-significant-rise-in-complaints-to-gphc-about-pharmacists/20207843.article 
[51] Food and Drug Administration, United States (2020) Coronavirus (COVID-19) Update: FDA Issues Emergency Use Authorization for Potential COVID-19 Treatment. FDA News Release.

https://www.fda.gov/news-events/press-announcements/coronavirus-covid-19-upd ate-fda-issues-emergency-use-authorization-potential-covid-19-treatment

[52] Dong, L., Hu, S. and Gao, J. (2020) Discovering Drugs to Treat Coronavirus Disease 2019 (COVID-19). Drug Discoveries \& Therapeutics, 14, 58-60.

[53] Rosenthal, M. (2020) ASHP Makes Recommendations for Pharmacy Readiness for COVID-19. Infectious Diseases Special Edition.

https://www.idse.net/Covid-19/Article/03-20/ASHP-Makes-Recommendations-forPharmacy-Readiness-for-COVID-19/57685

[54] Agampodi, T.C., Agampodi, S.B., Glozier, N. and Siribaddana, S. (2015) Measurement of Social Capital in Relation to Health in Low and Middle Income Countries (LMIC): A Systematic Review. Social Science \& Medicine, 128, 95-104. https://doi.org/10.1016/j.socscimed.2015.01.005

[55] McGregor, S., Henderson, K.J. and Kaldor, J.M. (2014) How Are Health Research Priorities Set in Low and Middle Income Countries? A Systematic Review of Published Reports. PLOS ONE, 9, e108787-e108787. https://doi.org/10.1371/journal.pone.0108787

[56] Adam, T. and de Savigny, D. (2012) Systems Thinking for Strengthening Health Systems in LMICs: Need for a Paradigm Shift. Health Policy and Planning, 27, iv1-iv3. https://doi.org/10.1093/heapol/czs084

[57] Reeves, A., Gourtsoyannis, Y., Basu, S., McCoy, D., McKee, M. and Stuckler, D. (2015) Financing Universal Health Coverage-Effects of Alternative Tax Structures on Public Health Systems: Cross-National Modelling in 89 Low-Income and Middle-Income Countries. The Lancet, 386, 274-280. https://doi.org/10.1016/S0140-6736(15)60574-8

[58] Schwerdtle, P., Morphet, J. and Hall, H. (2017) A Scoping Review of Mentorship of Health Personnel to Improve the Quality of Health Care in Low and Middle-Income Countries. Globalization and Health, 13, Article No. 77. https://doi.org/10.1186/s12992-017-0301-1

[59] Babar, Z. and Scahill, S. (2014) Barriers to Effective Pharmacy Practice in Low- and Middle-Income Countries. Integrated Pharmacy Research and Practice, 3, 25-27. https://doi.org/10.2147/IPRP.S35379

[60] Kretchy, I.A., Asiedu-Danso, M. and Kretchy, J.P. (2020) Medication Management and Adherence during the COVID-19 Pandemic: Perspectives and Experiences from Low- and Middle-Income Countries. Research in Social and Administrative Pharmacy, in press. https://doi.org/10.1016/j.sapharm.2020.04.007

[61] Sharma, U. (2020) IPA Requests PM to Allow Pharmacists to Conduct COVID-19 Tests and Offer Other Services.

https://www.expresspharma.in/covid19-updates/ipa-requests-pm-to-allow-pharmac ists-to-conduct-covid-19-tests-and-offer-other-services/

[62] United News of Bangladesh (2020) Rising Crisis of Hand Sanitizers and Liquid Handwashes in Market due to Corona Fear.

https://unb.com.bd/category/Bangladesh/rising-crisis-of-hand-sanitizers-and-liquid -handwashes-in-market-due-to-corona-fear/46579

[63] Dhaka Tribune (2020) Coronavirus Outbreak: DU Pharmacy Faculty Starts Making Hand Sanitizer.

https://www.dhakatribune.com/bangladesh/dhaka/2020/03/14/coronavirus-du-s-ph 
armacy-dept-makes-low-cost-hand-sanitizer

[64] Bdnews24.com (2020) BRAC University Supplies Hand Sanitiser to BSMMU as Coronavirus Spreads.

https://bdnews24.com/campus/2020/03/23/brac-university-supplies-hand-sanitiserto-bsmmu-as-coronavirus-spreads

[65] International Rescue Committee (2020) IRC Pharmacist Provides Refugee Women with Access to Medicine in Jordan. COVID-19 Response.

https://www.rescue.org/video/irc-pharmacist-provides-refugee-women-access-medi cine-jordan

[66] James, P.B., Jamshed, S. and Patel, I.B. (2016) Ebola Virus Disease: How Can African Pharmacists Respond to Future Outbreaks? Asian Pacific Journal of Tropical Disease, 6, 337-338. https://doi.org/10.1016/S2222-1808(15)61041-6

[67] American Society of Health-System Pharmacists (2020) COVID-19 Resource Center. https://www.ashp.org/COVID-19

[68] American Pharmacists Association, United States (2020) Pharmacists' Guide to Coronavirus. https://www.pharmacist.com/coronavirus

[69] European Association of Hospital Pharmacists (2020) EAHP COVID-19 Resource Centre.

https://www.eahp.eu/hp-practice/hospital-pharmacy/eahp-covid-19-resource-centr e

[70] International Pharmaceutical Federation (2020) Guidelines for Pharmacists and the Pharmacy Workforce. https://www.fip.org/coronavirus

[71] Centers for Disease Control and Prevention, United States (2020) Considerations for Pharmacies during the COVID-19 Pandemic.

https://www.cdc.gov/coronavirus/2019-ncov/index.html

[72] World Health Organization (2020) Rational Use of Personal Protective Equipment (PPE) for Coronavirus Disease (COVID-19).

https://apps.who.int/iris/bitstream/handle/10665/331498/WHO-2019-nCoV-IPCPP E use-2020.2-eng.pdf

[73] World Health Organization (2020) Risk Assessment and Management of Exposure of Health Care Workers in the Context of COVID-19. https://apps.who.int/iris/bitstream/handle/10665/331496/WHO-2019-nCov-HCW risk assessment-2020.2-eng.pdf 